\title{
Research on Evaluation of Logistics Transportation and Regional Economic Development Fitness
}

\author{
Zhenghang Zhou \\ School of Economics and Management \\ Hebei University of Science and Technology \\ Shijiazhuang, Hebei, China \\ 2534359965@qq.com
}

\begin{abstract}
In order to study the adaptability of regional logistics transportation and regional economy and promote the coordinated operation of logistics transportation and regional economic development, the paper selects 16 indicators related to logistics transportation and economic development, makes principal component analysis to evaluate and analyze the comprehensive development of the indicators, and constructs the fitness evaluation model, the data of Hebei Province from 2007 to 2016 are calculated. According to the fitness function, the results show that the comprehensive development level of regional economy is slightly higher than that of logistics transportation. The fitness value is above 0.4 , which does not reach a strong adaptive state, indicating that the logistics transportation and economic development are stable, but can still be improved. The speed of economic development has been rising steadily, but the development speed of logistics transportation has slowed down in the past two years. Therefore, in the future economic development, the construction of logistics transportation needs to be strengthened to guide the rapid economic development.
\end{abstract}

Keywords-Logistics transportation; Regional economic development; Principal component analysis; Fitness function

\section{INTRODUCTION}

With the development of the national economy, the growth momentum of logistics industry is very strong, and plays an irreplaceable role in economic development. In the regional economic system, logistics transportation is one of the important branches. They are coordinated and closely linked. On the one hand, logistics transportation promotes the prosperity of regional economic system. In today's regional economy, logistics construction occupies an important position in infrastructure construction. Frequent logistics transportation activities, increased work efficiency of logistics enterprises, and improved logistics transportation system make regional economic operation efficiency improved, and accelerate the process of urbanization. On the other hand, the rapid growth of regional economy promotes the development of logistics transportation industry, and the development of regional economy makes the demand of logistics transportation increase continuously. Regional development planning affects the direction of logistics transportation development. The shift of the focus of regional industry makes the focus of logistics transportation pattern shift accordingly. Therefore, it is necessary to study the adaptability of logistics transportation and regional economy. This paper studies the adaptability of logistics transportation and regional economy, analyses the results and puts forward some guiding suggestions, so as to promote the virtuous circle of regional economy and logistics transportation.

Scholars have studied regional economy and logistics transportation extensively. Danuta Kisperska-Moron [1] pointed out that the changes of inventory levels in various sectors of the economy reflect the changes of service modes in the logistics industry. Conversely, the changes of operation modes in the logistics industry play an important role in the development of economic transformation. The promotion effects. Doug Leduc[2] based on the supply chain perspective found that the logistics industry needs infrastructure, logistics functions or links can bring horizontal industrial agglomeration, supply chain can bring vertical industrial agglomeration. Bai Qinghua[3] studies the impact of logistics industry agglomeration on regional economy by analyzing the agglomeration degree of logistics industry in different regions and summarizes the results. Starting from the internal mechanism of regional economy and logistics, Gaokang[4] constructed the coupling synergy model of regional economic subsystem and regional logistics subsystem and studied the coupling synergy degree of regional economy and logistics development . Based on theoretical analysis, Guo Hubin[5] constructs an evaluation index system for the coordinated development of regional logistics and regional economy and makes an empirical analysis on the coupling and coordination of regional logistics and regional economic development in the Yangtze River Delta by using the coupling degree model. Zhu Changzheng [6] and others used panel data model to analyze the impact of logistics industry agglomeration on urban economy.

The above article focuses on the relationship between regional economic development and logistics transportation but does not study the adaptability of the two in essence. In this paper, by constructing the development model of regional economy and logistics transportation suitability, the comprehensive level of their development is analyzed, the adaptability between regional economy and logistics transportation is judged, the relationship between regional economy and logistics transportation is analyzed, and the accurate guidance suggestions for regional economic development planning are given, and the regional economy is brought into full play. Cooperative ability with logistics transportation strategy. 


\section{SELECTION OF EVALUATION METHODS}

A. Comprehensive Development Level Evaluation Index

Firstly, the original data are standardized, and the formulas are as follows: $\lambda_{\mathrm{i}}=\left(X_{\mathrm{i}}-\bar{X}_{\mathrm{i}}\right) / S_{\mathrm{i}} ;(1)$

Among them, $\lambda_{i}$ the standardized value of the sample data of the first $\mathrm{i}$ index, $X_{\mathrm{i}}$ the original value of the first $\mathrm{i}$ index, $X_{\mathrm{i}}$ the average value of the sample data, $S_{\mathrm{i}}$ the standard deviation of the sample data of the first $i$ index.

Then, through the principal component analysis method, the logistics transportation development index and regional economic comprehensive index are screened and evaluated. The logistics transportation comprehensive development function is recorded as $T(\mathrm{x})$, and the regional economic comprehensive development evaluation function is recorded as $H(\mathrm{x})$. The evaluation function is constructed by the principal component score. The function formula is as follows:

$$
\begin{aligned}
& \mathrm{T}(\mathrm{x})=\left(\mathrm{a}_{1} T_{1}+\mathrm{a}_{2} T_{2}+\ldots+\mathrm{a}_{n} T_{n}\right) / \sum_{i=1}^{n} a_{i} ; \\
& \mathrm{H}(\mathrm{x})=\left(\mathrm{a}_{1} H_{1}+\mathrm{a}_{2} H_{2}+\ldots+\mathrm{a}_{n} H_{n}\right) / \sum_{i=1}^{n} a_{i} ;
\end{aligned}
$$

where $T(\mathrm{x})$ and $H(\mathrm{x})$ are the evaluation functions of the comprehensive development level of logistics transportation and regional economy, $T_{\mathrm{n}}$ is the score of the first $\mathrm{n}$ principal component selected in economic development, $a_{n}$ is the variance contribution rate of the first $\mathrm{n}$ principal component.

\section{B. Fitness evaluation function model}

Logistics transportation is the motive force of urban economic development, and the development of urban economy can promote the development of transport industry. They develop and promote each other in order to achieve common and coordinated development. In revising Darwin's theory and reinterpreting the principle of natural selection, modern synthesis theory replaces "survival" with "reproduction" to measure adaptation, and changes "survival of the fittest" to "reproduction of the fittest" and uses the new concept of fitness to quantitatively express the degree of adaptation, and to index the comprehensive level of economy and logistics transportation. Processing, the formula is: $\theta_{1}=T(\mathrm{x})+\mathrm{c} ; \theta_{1}=H(\mathrm{x})+\mathrm{c} ;(3)$ among them, $\mathrm{c}$ is constant, $\theta_{1}$ and $\theta_{2}$ are the comprehensive development level index of logistics transportation and regional economy.

Based on the existing research, this paper uses the fitness function model, the formula is:

$$
\sigma=\sqrt{\theta_{1} \times \theta_{2} /\left(\theta_{1}+\theta_{2}\right)^{2}}=\sqrt{(T(\mathrm{x})+\mathrm{c}) \times(H(\mathrm{x})+\mathrm{c}) /(T(\mathrm{x})+H(\mathrm{x})+2 \mathrm{c})^{2}}
$$

;(4)Among them, for the adaptability of logistics transportation and regional economic situation, $\sigma \in(0,1)$.

Table 1 divides the adaptability of logistics transportation and economic development into the following categories:
TABLE I GRADE TABLE OF LOGISTICS TRANSPORT AND ECONOMIC DEVELOPMENT FITNESS

\begin{tabular}{llllll}
\hline Grade & Weak & Weaker & Commonly & Stronger & Strong \\
\hline Fitnes-s & $0-0.2$ & $0.2-0.4$ & $0.4-0.6$ & $0.6-0.8$ & $0.8-1$ \\
\hline
\end{tabular}

III. ADAPTABILITY EVALUATION AND ANALYSIS OF LOGISTICS TRANSPORTATION AND ECONOMIC DEVELOPMENT

\section{A. Establishment of Evaluation Index System and Data Sources}

According to the characteristics of systematicness, efficiency and scientificity in the construction of index system, this paper selects 16 indexes, such as the length of transportation route, the quantity of transportation means, the gross domestic product and the level of residents' consumption and applies principal component analysis and fitness function model to the logistics transportation and economy of Hebei Province from 2007 to 2016. The relevant data of the development are analyzed. The data mainly come from Hebei Economic Yearbook and Hebei Statistical Bulletin of National Economic and Social Development. The index system is shown in Table 2.

\begin{tabular}{|c|c|}
\hline $\begin{array}{l}\text { Index } \\
\text { assignment }\end{array}$ & evaluating indicator \\
\hline \multirow{6}{*}{$\begin{array}{l}\text { Logistics } \\
\text { Transportation } \\
\text { Scale Index }\end{array}$} & Transport Line Length (X1) \\
\hline & Transportation vehicle ownership (X2) \\
\hline & Passenger traffic (X3) \\
\hline & Passenger turnover (X4) \\
\hline & Cargo turnover (X5) \\
\hline & Port cargo throughput (X6) \\
\hline \multirow{2}{*}{$\begin{array}{l}\text { Logistics } \\
\text { Transport } \\
\text { Development } \\
\text { Indicators }\end{array}$} & Total investment in fixed assets (X7) \\
\hline & Scale of Logistics Enterprises(X8) \\
\hline \multirow{5}{*}{$\begin{array}{l}\text { Indicators of } \\
\text { regional } \\
\text { economic scale }\end{array}$} & Employment (X9) \\
\hline & Population (X10) \\
\hline & Urbanization rate of resident population (X11) \\
\hline & Gross regional product (X12) \\
\hline & Per capita GDP (X13) \\
\hline \multirow{3}{*}{$\begin{array}{l}\text { Indicators of } \\
\text { regional } \\
\text { economic } \\
\text { development }\end{array}$} & The ratio of tertiary industry to GDP (X14) \\
\hline & Resident Consumption Level (X15) \\
\hline & Consumer Price Index (X16) \\
\hline
\end{tabular}

TABLE II LOGISTICS TRANSPORTATION AND REGIONAL ECONOMIC INDICATORS SYSTEM

\section{B. Evaluation of Comprehensive Development Level}

The selected data will be simplified and transformed into growth rate. According to the comprehensive development evaluation method, the original data will be standardized and processed by SPSS software for principal component analysis. The principal component chooses the part whose eigenvalue is greater than 1 and calculates the contribution rate and the cumulative contribution rate.

The cumulative contribution rate of logistics transportation and economic development is $96.734 \%$ and $97.5 \%$ respectively. It meets the general requirement of the original index information quantity. Formulas are used to construct the 
evaluation functions of economic development and logistics transportation $T(\mathrm{x})$ and $H(\mathrm{x})$.

$$
T(\mathrm{x})=0.805 T_{1}+0.195 T_{2} ; H(\mathrm{x})=0.813 H_{1}+0.187 H_{2} ;(5)
$$

Taking the extracted principal component score into equation (5), the comprehensive development level index of logistics transportation and regional economy in Hebei Province from 2007 to 2016 is obtained, as shown in table 3.

TABLE III DEVELOPMENT LEVEL INDEX OF LOGISTICS TRANSPORTATION AND REGIONAL ECONOMIC COMPREHENSIVE IN HEBEI PROVINCE, 2007-2016

\begin{tabular}{lll}
\hline year & $\begin{array}{l}\text { Logistics } \\
\text { transportation }\end{array}$ & Regional economic development \\
\hline 2007 & -1.097 & -1.080 \\
2008 & -0.821 & -0.905 \\
2009 & -0.593 & -0.733 \\
2010 & -0.728 & -0.395 \\
2011 & -0.255 & -0.131 \\
2012 & 0.240 & 0.139 \\
2013 & 0.554 & 0.431 \\
2014 & 0.987 & 0.675 \\
2015 & 0.789 & 0.868 \\
2016 & 0.924 & 1.130 \\
\hline
\end{tabular}

Table 3 shows that the comprehensive development level index of logistics and transportation has been on the rise since 2008-1.097, peaking at 0.987 in 2014 , decreasing to 0.789 in 2015 and rising again to 0.924 in 2016. The index of comprehensive development level of regional economy has been rising steadily from 2007 to 2016, reaching a maximum of 1.13 by 2016 . Through the above data analysis, the correlation between logistics transportation and regional economic comprehensive development index in Hebei Province is not strong. When the development of logistics transportation slows down, regional economic development is still rising steadily. This shows that the correlation between logistics transportation and regional economy is not strong, so we should adjust the development direction of logistics transportation in order to adapt to regional economy. Development.

\section{Fitness Evaluation and Analysis}

Through the above formulas, the adaptability of logistics transportation and regional economic development can be calculated. The results are shown in Table 4.

TABLE IV FITNESS OF LOGISTICS TRANSPORTATION AND REGIONAL ECONOMIC COMPREHENSIVE DEVELOPMENT

\begin{tabular}{lll}
\hline Year & Fitness & Adaptive grade \\
\hline 2007 & 0.460 & commonly \\
2008 & 0.486 & commonly \\
2009 & 0.493 & commonly \\
2010 & 0.468 & commonly \\
2011 & 0.490 & commonly \\
2012 & 0.497 & commonly \\
2013 & 0.500 & commonly \\
2014 & 0.603 & Stronger \\
2015 & 0.497 & commonly \\
2016 & 0.496 & commonly \\
\hline
\end{tabular}

As shown in Table 4 above, the adaptability of logistics transportation and regional economy has gone through four stages. From 2007 to 2009, the fitness increased steadily, reaching 0.493 , slightly decreased in 2010 to 0.468 , and then continued to rise from 2011 to 2013, reaching 0.5 in 2013, and peaking in 2014 in logistics transportation and regional economy, when the fitness reached 0.603 . It shows that the economic development at this time provides resources and direction for the development and improvement of logistics transportation and makes the logistics transportation capacity leap forward at this stage. In 2015, the comprehensive development adaptability was reduced to 0.497 . In 2016 , the comprehensive development adaptability was basically the same as in 2015, which means that the logistics transportation development was backward currently. Regional economy needs the improvement of logistics transportation to ensure the rapid and stable development of regional economy.

\section{CONCLUSION}

Through the study of the comprehensive level of logistics transportation and regional economic development, this paper draws the conclusion that the strength of logistics transportation capacity will affect economic development. Logistics transportation capacity lags economic development capacity, which will restrict economic development to a certain extent. The adaptability of logistics transportation capacity and economic development in Hebei Province shows a tortuous upward trend. The adaptability grade is above 0.4, which 
indicates that logistics transportation and economic development are in a stable situation, but it can still be improved. The speed of economic development has been steadily rising. Therefore, in the future development, we should devote great efforts to the construction of logistics transportation, to make logistics transportation more suitable for the development of regional economy, to make more contributions to the development of regional economy.

The fitness evaluation method established in this paper can predict the fitness of logistics transportation and regional economic development, put forward reasonable planning and suggestions for relevant government departments, make accurate development control, and coordinate logistics transportation and regional economic development, so that they can promote each other and develop together. At present, the research of logistics transportation and regional economic adaptability belongs to the exploratory period. These variable factors need to be fully considered in the future research. Moreover, how to adjust their adaptability measurement, determine the mode and scale of logistics transportation, and realize the optimal direction of regional economic development is also the focus of future research.

\section{REFERENCES}

[1] Danuta Kisperska-Moron. Logistics Change During the Transition Period in the Polish h Economy.

[2] Doug Leduc. Logistics Cluster Holds Great Promise for Fort Wayne [J]. Area Economy. Knight Ridder Tribune Business News, 2004(12).

[3] Bai Qinghua. Empirical Analysis of the Impact of Logistics Industry Agglomeration on Regional Economic Growth [J]. Business Economic Research, 2018 (16): 86-88.

[4] Gaokang, Wang Maochun, Zhang Bukuang. Evolution and Spatial Difference of Coupling and Coordination of Regional Economy and Logistics in Pan-Pearl River Delta [J]. Price Monthly, 2018 (09): 49-55.

[5] Guo Hubin, Qiyuan. Research on coordinated development of regional logistics and regional economy in the Yangtze River Delta based on coupling model [J]. Industrial technology economy, 2018,37(10): 51-58.

[6] Zhu Changzheng, Zhao Liang. Urban Comparison of the Impact of Logistics Industry Agglomeration on Regional Economy [J]. Business Economic Research, 2018 (18): 99-101. 